\title{
Different expression of $P p-L T P 1$ and accumulation of Pru p 3 in fruits of two Prunus persica L. Batsch genotypes
}

\author{
Alessandro Botton a, Mara Vegro b, Filippo De Franceschi a, Angelo Ramina ${ }^{\text {a }}$, \\ Carla Gemignani ${ }^{\mathrm{c}}$, Guido Marcer ${ }^{\mathrm{c}}$, Gabriella Pasini ${ }^{\mathrm{b}}$, Pietro Tonutti ${ }^{\mathrm{a}, *}$ \\ ${ }^{a}$ Department of Environmental Agronomy and Crop Science, University of Padova, Viale dell'Università 16, Agripolis, 35020 Legnaro (Padova), Italy \\ ${ }^{\mathrm{b}}$ Department of Agricultural Biotechnology, University of Padova, Viale dell'Università 16, Agripolis, 35020 Legnaro (Padova), Italy \\ ${ }^{\mathrm{c}}$ Department of Environmental Medicine and Publich Health, University of Padova, Via Giustiniani 2, 35128 Padova, Italy
}

Received 24 February 2006; accepted 28 February 2006

Available online 24 March 2006

\begin{abstract}
The full-length cDNAs of $P p$-LTP1 and Pp-LTP2, two members of the lipid transfer protein (LTP) multigene family in peach (Prunus persica L. Batsch), have been isolated along with the proximal promoter and the complete genomic sequence of $P p$ - $L T P 1$. As observed in other plant species, $P p$ $L T P 1$ is organized in two exons and, according to the deduced amino acid sequence of the secreted protein, it encodes the $9 \mathrm{kDa}$ allergenic protein Pru $\mathrm{p}$ 3. $P p-L T P 1$ transcripts and Pru $\mathrm{p} 3$ protein markedly accumulate in epicarp of ripe fruit in all of the peach and nectarine varieties examined (including 'Royal Gem') with the exception of 'Rita Star' that shows weak specific mRNA hybridization signal and no Pru p 3 accumulation. SDS-PAGE clearly displays a different banding pattern in correspondence of $9 \mathrm{kDa}$ between 'Rita Star' and 'Royal Gem'. In immunoblotting analysis, performed using sera of eight LTP pos+ patients, a strong band is present when using 'Royal Gem' epicarp extract but not in the case of 'Rita Star'. According to these data, 'Rita Star' appears an interesting model to better elucidate the role of LTP in fruit development and allergenic reactions.
\end{abstract}

(C) 2006 Elsevier Ireland Ltd. All rights reserved.

Keywords: Food allergy; Gene expression; Lipid transfer protein; Peach epicarp; Pru p 3 protein

\section{Introduction}

Lipid transfer proteins (LTPs) belong to the group 14 of the pathogenesis-related (PR) proteins [1]. LTP role in plant defence mechanisms and in the control of responses to pathogen attack has been recently reinforced [2-4]. However, considering that these proteins are widespread in nature, particularly abundant in aerial plant organs and encoded by multigene families, different functions have been hypothesized for LTPs. A role in transporting lipid molecules to the outer layers of plant organs, in embryogenesis and in abiotic stress response has been also proposed [5]. The multiple function of LTPs is also supported by the presence of isoforms showing moderate levels of amino acid sequence identity and different gene expression patterns [6-9]. Jung et al. [4] demonstrated that three LTP genes in pepper are differentially regulated by pathogens, abiotic and environmental stresses. More recently,

\footnotetext{
* Corresponding author. Tel.: +39049 8272845; fax: +390498272850.

E-mail address: pietro.tonutti@unipd.it (P. Tonutti).
}

Gao et al. [10] found a large sequence variation between the upstream regions of two Mal d 3 (a non-specific LTP of apple) genes possibly resulting in differential expression profiles induced by multiple factors.

LTPs have also been recognized as allergenic proteins in several plant foods (reviewed in [11]) including Rosaceae fruits. A number of allergenic LTPs have been isolated within members of this family as in the case of peach where the major allergen, Pru p 3 (originally named Pru p 1), has been extensively characterized in terms of protein sequence [12], fruit tissue localization [13], immunological properties of the natural and recombinant forms [14], stability following chemical and physical treatments [15,16], gene expression pattern in reproductive organs [9]. Allergic reactions to fresh fruits are mostly associated with the oral allergy syndrome (OAS) [17] and allergenicity has been reported to be higher in peels than in pulp of Rosaceae fruits [18]. This is due to the more abundant accumulation of the allergenic protein in the epidermal fruit tissues as evidenced by Carnés et al. [19] and Brenna et al. [20]. In previous works, Diaz-Perales et al. [21] isolated the cDNA encoding the peach allergen, whereas 
Botton et al. [9] cloned two partial cDNAs, $P p-L T P 1$ and $P p$ $L T P 2$, and demonstrated that only transcripts of $P p-L T P 1$, encoding Pru p 3, accumulate in epicarp of the peach variety 'Springcrest' throughout fruit development, reaching the highest level at ripening.

In this paper, we report the isolation of full-length cDNAs of $P p-L T P 1$ and $P p-L T P 2$, the characterization of Pp-LTP1 proximal promoter and the different accumulation of $P p$ LTP1 transcripts and the encoded peptide (Pru p 3) in the epicarp of two peach genotypes.

\section{Materials and methods}

\subsection{Plant material and nucleic acids extraction}

Fruits of peach varieties 'Royal Gem' (yellow flesh) and 'Zorzi' (white flesh), of nectarine varieties 'Rita Star' and 'Maria Dorata' (yellow flesh), and 'Early Giant' (white flesh), and of flat type (Platicarpa, white flesh) grown under the same conditions at the Province of Verona Experimental Farm (Ponton, Verona, Italy), were harvested in correspondence of commercial ripeness. Fruits have been selected according to flesh firmness and ethylene evolution assessed as reported by Tonutti et al. [22]. Samples to be analyzed correspond to fruits collected at harvest (T0) and after storage at different conditions. A first homogeneous group of fruits was maintained in air (A) at room temperature (about $25^{\circ} \mathrm{C}$ ) and allowed to ripen for a variable period (from 3 to 7 days) according to the variety characteristics, while a second group was stored at $4{ }^{\circ} \mathrm{C}$ for 3 weeks (R). A third lot of fruits was treated immediately after harvest at room temperature with $500 \mu \mathrm{l} / \mathrm{l}$ of propylene (an ethylene analogue) for $72 \mathrm{~h}$ and then kept in air for $24 \mathrm{~h}$. Epicarp samples were immediately frozen in liquid nitrogen and stored at $-80{ }^{\circ} \mathrm{C}$ for further analysis. Total RNA was extracted as described by Ruperti et al. [23] with little modifications as indicated by Dal Cin et al. [24]. Young leaves were sampled from peach cv 'Santa Lucia' for genomic DNA isolation performed using the Dneasy Plant Mini Kit (Qiagen, Milano, Italy).

\subsection{Rapid amplification of cDNA ends (RACE)}

Rapid amplification of cDNA ends was performed using the SMART ${ }^{\mathrm{TM}}$ RACE cDNA Amplification Kit (BD Biosciences Clontech, Mountain View, CA, USA) following the instructions provided by the producer. Gene-specific primers (GSP) used to obtain the full-length cDNAs were designed as follows-GSP1: 5'-ACTCCGGGGACGCTGGCGGAAAGC$3^{\prime}$ and GSP2: 5'-TAGCGCGTCCACTAACTGCGCCACTG-3' for $P p$-LTP1; GSP1: 5'-GGCAAGCCCAGCATTTGCATTGGGGTAA- $3^{\prime}$ and GSP2: 5'-CCAATGCAAATGCTGGGCTTGCCGC- $3^{\prime}$ for $P p-L T P 2$.

\subsection{Cloning of Pp-LTP1 gene}

Genomic sequence of Pp-LTPl was obtained by PCR amplification of genomic DNA using primers designed on the basis of $5^{\prime}$-UTR and $3^{\prime}$-UTR of the full-length cDNA. Primers were as follows-5LTPSPC1: 5'-GCTTACAAATCCGTTTCAAACTCC-3'; 3LTPSPC1: 5'-CGTCGTGAGGAATCCCTAAGTG-3'. PCR reaction was performed using the PerkinElmer GeneAmp PCR system 9700 (Applied Biosystems, Foster City, CA, USA) on 100 ng of genomic DNA with $0.1 \mathrm{U}$ of Taq DNA Polymerase (Amersham Biosciences, Uppsala, Sweden) in $1 \times$ buffer with $\mathrm{MgCl}_{2} 1.5 \mathrm{mM}$, dNTPs $0.2 \mathrm{mM}$ and $50 \mathrm{pmol}$ of both primers. After $5 \mathrm{~min}$ at $94^{\circ} \mathrm{C}, 38$ cycles were performed at $94{ }^{\circ} \mathrm{C}$ for $30 \mathrm{~s}$, at $63{ }^{\circ} \mathrm{C}$ for $30 \mathrm{~s}$ and at $72{ }^{\circ} \mathrm{C}$ for $45 \mathrm{~s}$. A final step at $72{ }^{\circ} \mathrm{C}$ for $7 \mathrm{~min}$ was also performed. PCR products were separated by electrophoresis in $1.5 \%$ agarose gel and stained with ethidium bromide. The expected band corresponding to $P p-L T P 1$ was excised and purified from agarose gel using Minelute ${ }^{\mathrm{TM}}$ Gel Extraction Kit (Qiagen). The band was subcloned into $\mathrm{pGem}^{\circledR}-\mathrm{T}$ easy vector (Promega, Milano, Italy) following the instruction manual and sequenced at CRIBI (University of Padova, Italy) using Big Dye Terminator v 3.1 Kit (Applied Biosystems).

\subsection{Cloning of proximal promoter}

A home-made genome walking approach was used to isolate a portion of $P p-L T P 1$ proximal promoter. An adapted AFLP protocol as developed by Vos et al. [25] was used for restriction-ligation steps. The main adaptations were related to the use of only one enzyme and specific adaptors designed according to the restriction site generated by the used endonuclease. Genomic DNA (500 ng) of cv 'Santa Lucia' was digested with EcoRI, ApaI, BamHI and $X b a \mathrm{I}$ restriction enzymes (NEB, Ipswich, MA, USA) chosen among those not present in the sequence of the full-length cDNA. Adaptors sequences used in the ligation (Sigma-Genosys Ltd., Lake Front Circle, The Woodlands, TX, USA) were as follows $\left(5^{\prime}-3^{\prime}\right.$ oriented)—EcoRI adaptor1: GAATTGGTACGCAGTCTACGAGGTACGCAGTCTTCAGTC and EcoRI adaptor2: CGTAGACTGAAGACTGCGTACCTCGTAGACTGAGACTGCGTACCAATTC; ApaI adaptor1: GGGCCGCATGCGTCAGATGCTCTACGAGGTACGCAGTCTTCAG and ApaI adaptor2: AGACTGCGTACCTCGTAGAGCATCTGACGCATGCGGCCC; BamHI adaptor1: GGATCGGTACGCAGTCTACGAGGTACGCAGTCTTCAGTC and BamHI adaptor2: CGTAGACTGAAGACTGCGTACCTCGTAGACTGAGTACCGATCC; $X b a$ I adaptor 1: TCTAGGGTACGCAGTCTACGAGGTACGCAGTCTTCAGTC and XbaI adaptor2: CGTA GACTGAAGACTGCGTACCTCGTAGACTGCGTACCCTAGA. A 1:10 dilution of the above reaction was used in the PCR amplification performed with gene-specific primers and adaptor-specific primers. Nested primers were also designed on the $5^{\prime}$ of $P p-L T P 1$ open reading frame to further check the specificity of PCR products-GSP1.1: 5'-CTTGAGCAATGGGCACGCTCACAA-3'; GSP1.2: 5'-ACTATGATGATGGAAGAAAAAAGGAG-3'; GSP1.3: 5'-TTTGTAAGCACTTGATTTGAGGAAC- $3^{\prime}$. All amplification reactions were performed using the Perkin-Elmer GeneAmp PCR system 2700 (Applied Biosystems) with $0.6 \mathrm{U}$ of AmpliTaq Gold ${ }^{\circledR}$ DNA Polymerase (Applied Biosystems) to achieve specificity, in $1 \times$ PCR buffer, dNTPs $0.5 \mathrm{mM}, 20 \mathrm{pmol}$ of gene-specific 
primer and 10 pmol of adaptor-specific primer in a final volume of $25 \mu \mathrm{l}$. After a denaturation step at $95{ }^{\circ} \mathrm{C}$ for $10 \mathrm{~min}$, 5 cycles were performed at $94{ }^{\circ} \mathrm{C}$ for $30 \mathrm{~s}$, at $66^{\circ} \mathrm{C}$ for $30 \mathrm{~s}$ and at $72{ }^{\circ} \mathrm{C}$ for $2 \mathrm{~min}$, followed by 40 cycles at $94{ }^{\circ} \mathrm{C}$ for $30 \mathrm{~s}$, at $62{ }^{\circ} \mathrm{C}$ for $30 \mathrm{~s}$ and at $72{ }^{\circ} \mathrm{C}$ for $2 \mathrm{~min}$. A final hold at $72{ }^{\circ} \mathrm{C}$ for $10 \mathrm{~min}$ was also carried out. Negative controls were performed with a single primer, either the gene-specific or the adaptor-specific one, to exclude the amplicons not given by the couple. PCR products were separated by gel electrophoresis in $1.5 \%$ agarose. The bands amplified by the couple of primers were excised and purified from agarose by means of Minelute $^{\mathrm{TM}}$ Gel Extraction Kit (Qiagen). The DNA fragments were subcloned and sequenced.

\subsection{Sequence analyses}

DNASTAR suite (DNASTAR Inc., Madison, WI, USA) was mainly used to manage sequences, assess identity, deduce amino acid sequences and analyze molecular weights and isoelectric points. SignalP 3.0 server program (www.cbs.dtu.dk/services/SignalP/) was used to detect signal peptides [26-28] and Homodeller 2.0 program (http://redpoll.pharmacy.ualberta.ca/homodeller/) was chosen to predict the three-dimensional structures of the two proteins. Consensus splicing motifs of Pp-LTPl genomic sequence were detected using NetGene2 Web Server (www.cbs.dtu.dk/services/NetPGene/) [29]. Computational analysis of Pp-LTPl proximal promoter was performed by PlantCare (http://intra.psb.ugent.be:8080/PlantCARE/) [30] and PLACE (www.dna.affrc.go.jp/PLACE/) [31] programs.

\subsection{Gene expression analysis}

Northern analysis was carried out on total RNA $(15 \mu \mathrm{g})$ using Pp-LTP1 probe (accession number AY093700) as described by Botton et al. [9].

\subsection{Protein extraction}

Peach proteins were extracted from ripe 'Rita Star' and 'Royal Gem' fruits using a given amount of homogenized epicarp diluted 1:3 (w/v) in 0.01 M PBS, pH 7.0, with $20 \%$ insoluble polyvinylpolypyrrolidone (PVPP) (Sigma, Milan, Italy) and $2 \%$ ascorbic acid (Sigma). After an extraction of $60 \mathrm{~min}$ at $4{ }^{\circ} \mathrm{C}$ in continuous stirring, the material was centrifuged at $12,000 \times g$ for $15 \mathrm{~min}$. The supernatant was dialyzed against water overnight in $3.5 \mathrm{kDa}$ membranes (Spectra Por, Spectrum Laboratories, Inc., Rancho Dominguez, CA, USA) and concentrated to achieve a final protein concentration of $8 \mathrm{mg} / \mathrm{ml}$ as measured by nitrogen quantification. These extracts were used for SDS-PAGE analysis and for LTP purification.

\subsection{Nitrogen quantification}

Samples were mineralized according to the method of Hach et al. [32] and nitrogen quantified by the AOAC method 33.056.

\subsection{SDS-PAGE}

The extracted proteins were analyzed by SDS-PAGE according to Laemmli [33] with a total polyacrylamide concentration of $16 \%$. An aliquot of protein extract was diluted with 0.3 volumes of $1.33 \mathrm{M}$ Tris- $\mathrm{HCl}$ buffer, $\mathrm{pH} 7.4$, containing $8 \%(\mathrm{w} / \mathrm{v}) \mathrm{SDS}, 10 \%(\mathrm{v} / \mathrm{v})$ 2-mercaptoethanol and 40\% (w/v) glycerol and heated at $100{ }^{\circ} \mathrm{C}$ for $5 \mathrm{~min} 50 \mu \mathrm{g}$ of total protein of each sample were loaded on the gel. Electrophoresis was run at $50 \mathrm{~mA}$ constant. Gels were stained with Coomassie Brilliant Blue according to Koenig et al. [34] or used for blotting. Molecular weight standard proteins (Bio-Rad, Hercules, CA, USA) were phosphorilase $\mathrm{B}(97.4 \mathrm{kDa})$, bovine serum albumin (66.2 kDa), ovalbumin (45 kDa), carbonic anhydrase $(31 \mathrm{kDa})$, soy trypsin inhibitor $(21.5 \mathrm{kDa})$ and lisozyme $(14.4 \mathrm{kDa})$.

\subsection{Purification of LTP}

LTP was purified from 'Royal Gem' peach epicarp extract by gel filtration (Sephadex G-50) using a $36 \times 1.6$ column at a constant flow of $1 \mathrm{ml} / \mathrm{min}$. The column was equilibrated and eluted with PBS 0.01 M, pH 7.2. Fractions were collected every $8 \mathrm{~min}$ and absorbance monitored at $280 \mathrm{~nm}$. The presence of LTP in the fractions was identified by SDS-PAGE and IgE immunoblotting with pooled sera. The fractions containing LTP were pooled, concentrated two times and used for rabbit antiserum production (Primm S.r.l., Milano, Italy).

\subsection{Immunoblotting}

After PAGE separation, proteins were transferred onto nitrocellulose membranes (Millipore, Billerica, MA, USA) by semi-dry transfer cell (Bio-Rad), blocked with Tris Buffer Saline (TBS) containing 0.05\% Tween 20 (TBS-T) and 5\% skin milk powder (M-TBS-T) for $4 \mathrm{~h}$ and then incubated overnight with the rabbit antibody diluted 1:8000 in M-TBS-T. After five washings with M-TBS-T, blots were incubated for $1 \mathrm{~h}$ with anti-rabbit IgG alkaline phosphatase conjugate (1:6000) as the secondary antibody. Immunoenzymatic activity on blots was revealed with 5-bromo-4-chloro-3-indolyl phosphatase and nitro-blue tetrazolium.

For detection of serum $\operatorname{IgE}$ binding to peach proteins the membranes, after blocking as described above, were incubated overnight with the serum of each of the 24 selected patient or pooled sera (see below). After five washings with M-TBS-T, blots were incubated for $1 \mathrm{~h}$ with anti-human $\operatorname{IgE}$ peroxidaseconjugate antibody (Sigma) diluted 1:6000 in M-TBS-T. After four washings with TBS, peroxidase activity was visualized by chemio-luminescence using the Super Signal detection kit (Pierce, Rockford, IL, USA). Pooled sera from both healthy subjects and patients with peach-unrelated allergy were used as negative controls.

\subsection{Patients sera}

Twenty-four consecutive outpatients were selected on the basis of positive serum peach-specific IgE test (CAP-FEIA 
System, Pharmacia, Uppsala). All sera were tested using an SDS-PAGE immunoblotting technique in order to point out the band at $9 \mathrm{kDa}$ typical of the major allergen of peach [16]. Since the LTP is the "true" allergen in symptomatic subjects [35], sera of eight LTP-positive patients were selected for the following study, pooled and used for detection of $\operatorname{IgE}$ binding to RG and RS protein extract. Five non-allergic people, in which peach-specific IgE were undetectable and the commercial skin prick tests negative were selected as negative controls in the following immunological tests.

\section{Results}

\subsection{Isolation of Pp-LTP1 and Pp-LTP2 full-length cDNAs}

Full-length cDNAs of the two peach lipid transfer proteins previously isolated as partial sequences [9] have been obtained using the RACE technique and sequences published in GenBank (AY620230 and AY093699 for Pp-LTP1 and Pp$L T P 2$, respectively). A fragment of $615 \mathrm{nt}$ has been isolated from mature fruit epicarp cDNA using primers specific for $P p-L T P 1$, while a longer fragment of $823 \mathrm{nt}$ has been obtained from non-pollinated ovary cDNA when $P p$-LTP2-specific primers were used.

Sequence comparison reveals that the two cDNAs share only $33.7 \%$ of identity at the nucleotide level (data not shown) and $48.7 \%$ of identity at the deduced amino acidic level (Fig. 1), however both showing the typical characteristics of lipid transfer proteins as the eight conserved cysteines and the lipid binding motifs (Asp-Arg-Gln and Cys-Gly-Val). Pp-LTP1 sequence contains a $354 \mathrm{nt}$ open reading frame encoding a protein of 117 amino acid residues. Bioinformatic analysis with SignalP server program indicates that the N-terminus contains an eukaryotic signal sequence with a cleavage site positioned

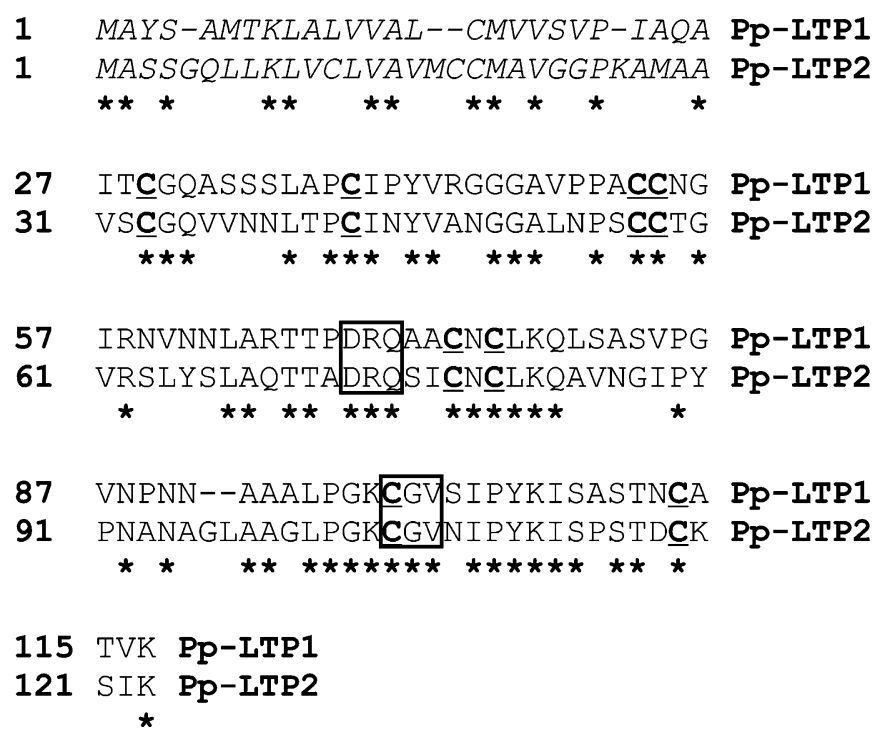

Fig. 1. Alignment of the deduced aminoacid sequences of Pp-LTP1 and PpLTP2. The identical amino acids are marked with an asterisk, the cysteines residues are shown in bold and underlined, and the lipid-binding motifs are boxed. The signal peptide is reported in italics in both sequences. between $\mathrm{Ala}^{26}$ and $\mathrm{Ile}^{27}$. The mature protein isoelectric point and molecular weight are 8.89 and $9.11 \mathrm{kDa}$, respectively. PpLTP2 protein (123 amino acids) is encoded by an open reading frame of $369 \mathrm{nt}$ and shares some features with Pp-LTP1. PpLTP2 has an isoelectric point of 8.50, a molecular weight of $9.53 \mathrm{kDa}$ and a signal peptide of 30 amino acids with the cleavage site between $\mathrm{Ala}^{30}$ and $\mathrm{Val}^{31}$. Marked differences between Pp-LTP1 and Pp-LTP2 signal peptide are evident when comparing the deduced amino acid sequences (Fig. 1).

Three-dimensional structures of the two proteins have been determined from primary sequence by homology modelling. According to the results provided by Homodeller program, the two peach lipid transfer proteins share a common structure with four $\alpha$-helixes folded by four disulphide bridges to form a long hydrophobic cavity aimed to lipid binding (data not shown).

\subsection{Genomic cloning and bioinformatic characterization of Pp-LTPI}

Specific primers designed on the $5^{\prime}$-UTR and $3^{\prime}$-UTR cDNA sequences of $P p$-LTPl have been used to obtain the complete genomic sequence of $P p$-LTP1. Two exons of 344 and $10 \mathrm{nt}$ are present and characteristic consensus splicing motifs typical of plant species are located between +345 and +354 (donor splice site, DSS), +493 and +511 (branch point, BrP), and +528 and +437 (acceptor splice site, ASS) (Fig. 2A). Deduced amino acid sequence of the secreted protein encoded by Pp-LTPl is identical to that reported by Diaz-Perales et al. [21] confirming that $P p-L T P 1$ encodes the allergenic protein Pru p 3.

A genome walking approach has been used to isolate a portion of $P p-L T P 1$ promoter, $786 \mathrm{bp}$ upstream from the translation initiation codon (Fig. 2B). Analysis of the Pp-LTP1 promoter region identified motifs showing similarity to the eukaryotic TATA and CAAT box consensus sequences: a TATA box and a putative CAAT box have been detected between -31 and -24 , and between -84 and -87 from the Transcrption Start Site (TSS), respectively. A number of cis-acting elements are also present in the promoter region of Pp-LTPl: in particular, tissue- and/or organ-specific elements, hormoneresponsive motifs and abiotic and biotic stress-related sequences have been identified.

\subsection{Screening of different varieties for Pp-LTP1 expression and Pru p 3 accumulation level}

Transcript accumulation of $P p-L T P 1$ and related protein level have been monitored in epicarp of six different peach and nectarine varieties (including the flat type Platicarpa) at commercial harvest and following three postharvest handlings (storage at room temperature, refrigerated storage, propylene treatment). Since five ('Royal Gem', 'Zorzi', 'Early Giant', 'Maria Dorata' and Platicarpa) of the six tested varieties showed, with the exception of the propylene-treatment samples, comparable transcript and protein accumulation patterns, only data of 'Royal Gem' (RG) representing this group will be herein reported. $P p-L T P 1$ transcripts markedly 


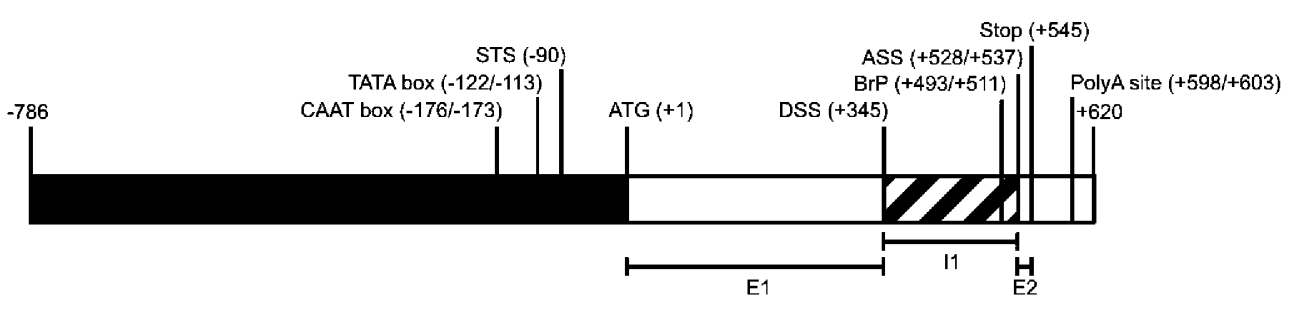

(A)

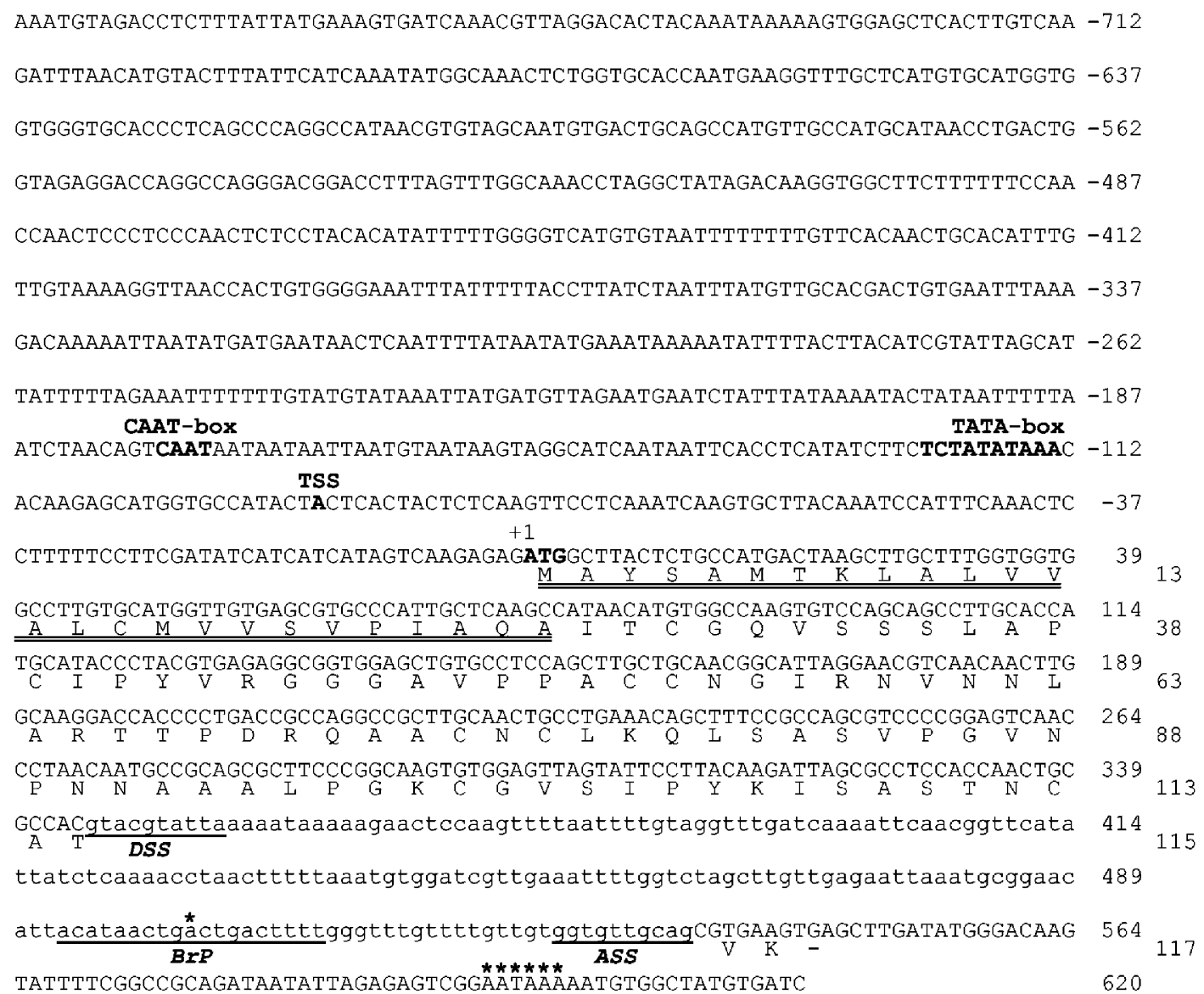

Fig. 2. Structure of Pp-LTP1 (A) and promoter main elements (B). CAAT box, TATA box, transcriptional start site (TSS) and start codon are indicated in bold. Splicing sites are underlined and reported in the intron sequence (lowercase): donor splicing site (DSS), branching point (BrP) and acceptor splicing site (ASS). Polyadenilation site is indicated by asterisks (*). Signal peptide (double underlined) is also included in the deduced amino acid sequence.

accumulate in the RG epicarp at commercial ripening and the same transcript level is detected after 8 days of storage at room temperature (about $25^{\circ} \mathrm{C}$ ) (Fig. 3). A marked hybridization signal has been detected in samples maintained at $4{ }^{\circ} \mathrm{C}$ for 3 weeks, whereas a reduced level of specific transcripts has been observed in propylene-treated samples. Differently from RG (and the other tested peach and nectarine varieties belonging to the above mentioned group), 'Rita Star' (RS) epicarp mRNA shows weak hybridization signals at commercial harvest and following the three postharvest treatments (Fig. 3). Pru p 3 accumulation analysis, assessed by Western blot using the polyclonal antibody, confirms the differences observed in terms of $P p-L T P 1$ gene expression between RG and RS. While in the former variety the presence of the protein is clearly detectable, particularly at commercial harvest and after room temperature storage, Pru p 3 protein has not been detected by the polyclonal antibody in RS epicarp in any of the considered samples (Fig. 3).

\subsection{SDS-PAGE}

The concentration of protein in epicarp extracts, measured by nitrogen quantification, was higher in RG than in RS. In particular, protein content in RG was $9.2 \mathrm{mg} / \mathrm{ml}$ whereas that of RS was $6.8 \mathrm{mg} / \mathrm{ml}$. However, total proteins were concentrated and an equal amount was loaded in the gel. Protein profile of 'Rita Star' and 'Royal Gem' epicarp extracts is shown in Fig. 4. The most prominent band in RG extract is 


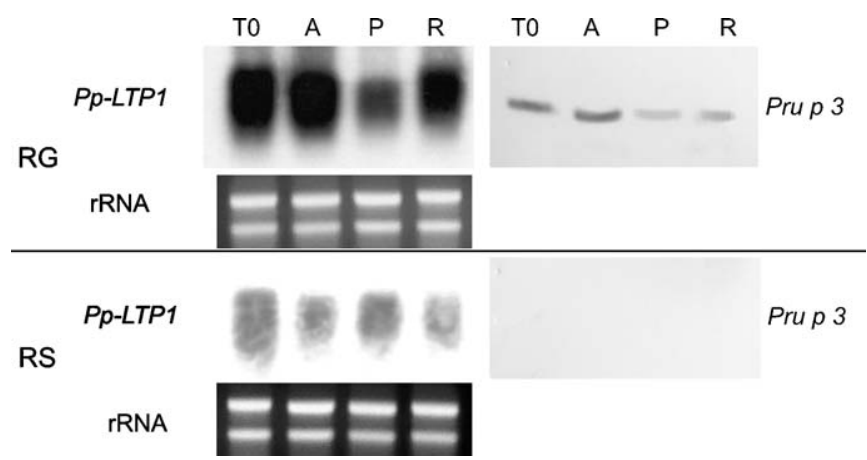

Fig. 3. Pp-LTP1 gene expression (left) and Pru p 3 accumulation (right) in 'Royal Gem' (RG) and 'Rita Star' (RS) epicarp. T0: commercial harvest; A: storage at room temperature for 8 days; P: propylene $(500 \mu \mathrm{l} / \mathrm{l}$ for $72 \mathrm{~h})$ treatment; R: storage at $4{ }^{\circ} \mathrm{C}$ for 3 weeks.

clearly visible at $9 \mathrm{kDa}$ whereas in RS this band is barely distinguishable. Other bands with molecular weights ranging from 9 to $70 \mathrm{kDa}$ are less visible. Coomassie Brilliant Blue has also stained some proteins, probably bound to polyphenols [36] and blocked at the top of the gel, that are not solubilized with reducing agent (2-ME) and detergent (SDS). The purified LTP shows only a band of $9 \mathrm{kDa}$ (Fig. 4).

\subsection{Immunoblotting}

To evaluate the LTP IgE binding of sera from 24 patients previously selected according to CAP-FEIA positivity, LTP purified protein was used in IgE immunoblotting experiments. A $9 \mathrm{kDa}$ band was recognized by the sera of $8 / 24$ subjects (data not shown). These LTP-positive sera were pooled and used to test the two varieties RG and RS already screened with rabbit polyclonal antibodies. The immunoblotting performed on RG epicarp extract shows the strongest signal corresponding to that detected using the purified LTP, whereas, in the case of RS, no detectable band is present (Fig. 5).

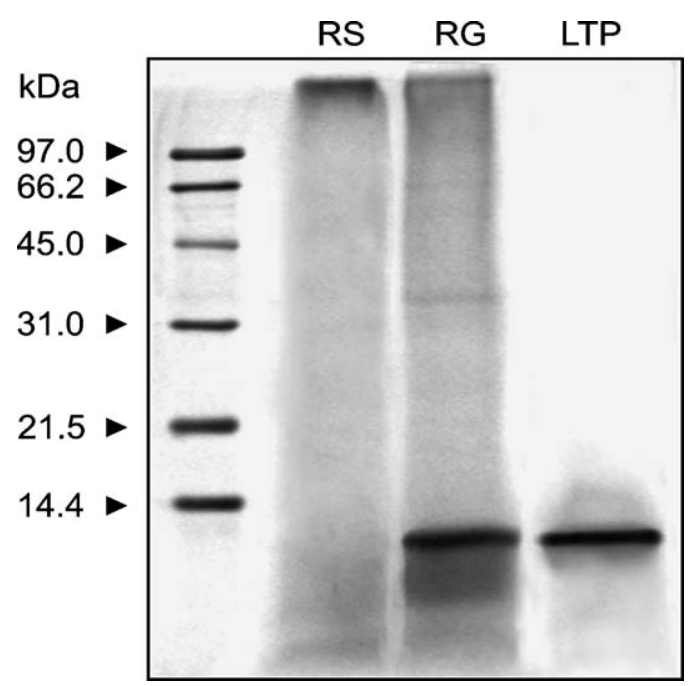

Fig. 4. SDS-PAGE of protein extracts from 'Rita Star' (RS), 'Royal Gem' (RG) epicarp and purified LTP extracts. Left lane: molecular weight standard.

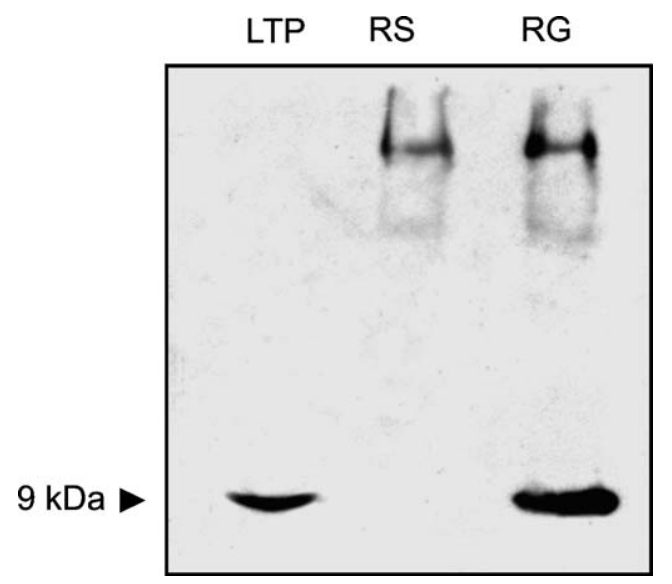

Fig. 5. Immunoblotting with pooled sera on purified LTP (LTP), 'Rita Star' (RS) and 'Royal Gem' (RG) epicarp protein extracts.

\section{Discussion}

Following the isolation of two peach LTP cDNA partial clones (Pp-LTP1 and $P p-L T P 2)[9]$ and the full-length cDNA clone encoding Pru p 3 [21], the characterization of Pp-LTP1 gene, its expression and the accumulation of the encoded allergenic protein (Pru p 3) in mature epicarp of some peach and nectarine genotypes are here reported.

Marked differences are evident by comparing the sequences of $P p-L T P 1$ and $P p-L T P 2$ : discrepancy observed in the signal peptide may suggest a different trafficking to the target destination of the two proteins as observed in apple for Mal d 3.01 and Mal d 3.02 [10]. Of the five amino acid residues identified by Garcia-Casado et al. [37] in Pru p 3 as antibody recognition sites (R39, T40, R44, K80 and K91), the last four are present in the Pp-LTP2 deduced amino acid sequence, although the position of K80 and K91 slightly shifts because of a different length of the protein. In addition, identity values of the three amino acid sequence regions (11-25, 31-45 and 71-80), defined as major IgE epitopes of Pru p 3 [37], vary from 53 to $90 \%$. The set of these data together with the different expression patterns detected in reproductive peach organs [9] suggest that these two members of the peach LTP family, formed at least by four to five genes [9], may play different roles.

$P p-L T P 1$ gene structure analysis reveals the presence of a single intron of $193 \mathrm{nt}$ positioned at the end of the open reading frame as found in LTP genes of other species as orange [38], cotton [39], rice [40], Arabidopsis thaliana [8], Sorghum vulgare [41], Brassica oleracea [42] and barley [43] but, interestingly, not in cultivated apple [10], that is phylogenetically closer to peach than the other mentioned species. The $P p$ LTP1 promoter region contains organ-, tissue- and cell-specific expression elements and hormone-responsive elements as evidenced in other plant LTP genes. A high number of lightresponsive elements are also present indicating a possible modulation of LTP transcription by this factor. Myb and Myc transcriptional factors binding sites have been identified together with specific sites enabling factor binding (NAC, DOF and WRKY). The high frequency of such sites confirms 
the involvement of $P p-L T P 1$ throughout peach fruit development as previously demonstrated [9]. Finally, only one element related to pathogen responsiveness and one motif related to cold-induced expression have been found: previous studies performed on pre-climacteric and climacteric fruits infected with Monilia laxa reported the absence of response to pathogen attack in terms of accumulation of $P p$-LTPl transcripts [9]. In this paper we also show that cold storage $\left(4^{\circ} \mathrm{C}\right)$ does not markedly affect expression level of $P p$-LTP1. However, it must be stressed that possible differences among samples are difficult to evaluate, since LTP transcripts are abundant in epicarp and Northern blot hybridization signal is quite strong.

Five of the six Prunus persica genotypes accumulate both $P p$-LTP 1 mRNA and Pru p 3 in the epicarp at commercial harvest. These five varieties seem to behave similarly to those described by Carnés et al. [19] showing that LTPs represent 25.72 and $26.06 \%$ of the total protein in fruits of 'Miraflores' and 'Springcrest' cultivar, respectively. Only cv 'Rita Star' shows particularly weak hybridization signals in Northern blot analysis and no protein was detected by the polyclonal antibody able to recognize the protein in other varieties. In addition, SDS-PAGE clearly shows a different banding pattern between RG and RS in correspondence of $9 \mathrm{kDa}$. Data concerning specific $P p$-LTPl transcript and related protein accumulation patterns in $\mathrm{RS}$ and $\mathrm{RG}$ have been confirmed in a second harvesting season characterized by different climatic conditions. Immunoblotting experiments performed with pooled sera of LTP-positive patients show a different IgE-binding capacity of the two protein extracts. In RS extract, no IgE binding protein is detected, whereas in $\mathrm{RG}$ a strong band is evidenced at $9 \mathrm{kDa}$.

In conclusion, our data clearly demonstrate that 'Rita Star' is characterized by low levels of $P p-L T P 1$ transcripts and undetectable accumulation of Pru p 3 protein in peel at commercial ripening, indicating that this may be considered a hypoallergenic peach variety. It must be stressed, however, that the techniques used may not be sufficiently sensitive to detect very low amount of allergenic proteins. Consequently, it cannot be excluded that minimal concentration of allergen may be adequate to bind specific $\operatorname{IgE}$, and, therefore, to elicit symptoms in sensitized patients, as reported by Moneret-Vautrin and Kanny [44], even though a reactive threshold dose for peach allergy has not been yet assessed.

Future researches are needed to evaluate whether the low levels of $P p-L T P 1$ transcripts and Pru p 3 protein correlate with peculiar physiological behavior or structural traits of RS fruit. In addition, further investigations, performed on allergic patients, should be carried out in order to assess its allergenic properties using allergological tests.

\section{Acknowledgements}

This work has been funded by the University of Padova (Progetti di Ateneo) and, in part, by the Italian Ministry of Education, University and Research (MIUR, PRIN project 2002078818) and the Italian Ministry of Agricultural and Forestry Policies (MIPAF, QUALIFRAPE project).

\section{References}

[1] L.C. Van Loon, E.A. van Strien, The families of pathogenesis-related proteins, their activities, and comparative analysis of PR-1 type proteins, Physiol. Mol. Plant Pathol. 55 (1999) 85-97.

[2] N. Buhot, J.P. Douliez, A. Jacquemard, D. Marion, V. Tran, B.F. Maume, M.L. Milat, M. Ponchet, V. Mikes, J.C. Kader, J.P. Blein, A lipid transfer protein binds to a receptor involved in the control of plant defence responses, FEBS Lett. 509 (2001) 27-30.

[3] A.M. Maldonado, P. Doerner, R.A. Dixon, C.J. Lamb, R.K. Cameron, A putative lipid transfer protein involved in systemic resistance signalling in Arabidopsis, Nature 419 (2002) 399-403.

[4] H.W. Jung, W. Kim, B.K. Hwang, Three pathogen-inducible genes encoding lipid transfer protein from pepper are differentially activated by pathogens, abiotic, and environmental stresses, Plant Cell Environ. 26 (2003) 915-928.

[5] J.C. Kader, Lipid-transfer proteins in plants, Annu. Rev. Plant Physiol. Plant Mol. Biol. 47 (1996) 627-654.

[6] M. Suelves, P. Puigdomenech, Different lipid transfer protein mRNA accumulate in distinct parts of Prunus amygdalus flowers, Plant Sci. 129 (1997) 49-56.

[7] M.A. Trevino, M.A. O'Connell, Three drought-responsive members of the nonspecific lipid-transfer protein gene family in Lycopersicon pennellii show different developmental patterns of expression, Plant Physiol. 116 (1998) 1461-1468.

[8] V. Arondel, C. Vergnolle, C. Cantrel, J.C. Kader, Lipid transfer proteins are encoded by a small multigene family in Arabidopsis thaliana, Plant Sci. 157 (2000) 1-12.

[9] A. Botton, M. Begheldo, A. Rasori, C. Bonghi, P. Tonutti, Differential expression of two lipid transfer protein genes in reproductive organs of peach (Prunus persica L. Batsch), Plant Sci. 163 (2002) 993-1000.

[10] Z.S. Gao, W.E. van de Weg, J.G. Schaart, I.M. van der Meer, L. Kodde, M. Laimer, H. Breiteneder, K. Hoffmann-Sommergruber, L.J.W.J. Gilissen, Linkage map positions and allelic diversity of two Mal d 3 (non-specific lipid transfer protein) genes in the cultivated apple (Malus domestica), Theor. Appl. Gen. 110 (2005) 479-491.

[11] G. Salcedo, R. Sanchez-Monge, A. Diaz-Perales, G. Garcia-Casado, D. Barber, Plant non-specific lipid transfer proteins as food and pollen allergens, Clin. Exp. Allergy 34 (2004) 1336-1341.

[12] E. Pastorello, C. Ortolani, C. Baroglio, V. Pravettoni, M. Ispano, M.G. Giuffrida, D. Fortunato, L. Farioli, M. Monza, L. Napolitano, M. Sacco, E. Scibola, A. Conti, Complete amino acid sequence determination of the major allergen of peach (Prunus persica) Pru p 1, Biol. Chem. 380 (1999) 1315-1320.

[13] R. Leonart, A. Cistero, J. Carreira, A. Batista, J. Moscoso del Prado, Food allergy: identification of the major IgE-binding component of peach (Prunus persica), Ann. Allergy 69 (1992) 128-130.

[14] A. Diaz-Perales, M.L. Sanz, G. Garcia-Casado, R. Sanchez-Monge, F.J. Garcia-Selles, M. Lombardero, F. Polo, P.M. Gamboa, D. Barber, G. Salcedo, Recombinant Pru p 3 and natural Pru p 3, a major peach allergen, show equivalent immunologic activity: a new tool for the diagnosis of fruit allergy, J. Allergy Clin. Immunol. 111 (2003) 628633.

[15] R. Asero, G. Mistrello, D. Roncarolo, S.C. de Vries, M.F. Gautier, C.L.F. Ciurana, E. Verbeek, T. Mohammadi, V. Knul-Brettlova, J.H. Akkerdaas, I. Bulder, R.C. Albarese, R. van Ree, Lipid transfer protein: a pan-allergen in plant-derived foods that is highly resistant to pepsin digestion, Int. Arch. Allergy Immunol. 122 (2000) 20-32.

[16] O.V. Brenna, C. Pompei, C. Ortolani, V. Pravettoni, L. Farioli, E.A. Pastorello, Technological processes to decrease the allergenicity of peach juice and nectar, J Agric. Food Chem. 48 (2000) 493-497.

[17] C. Ortolani, M. Ispano, E.A. Pastorello, A. Bigi, R. Ansaloni, The oral allergy sindrome, Ann. Allergy 61 (1988) 47-52.

[18] M. Fernandez-Rivas, M. Cuevas, Peels of Rosaceae fruits have a higher allergenicity than pulps, Clin. Exp. Allergy 29 (1999) 1239-1247.

[19] J. Carnés, E. Fernandez-Caldas, M.T. Gallego, A. Ferre, J. CuestaHerranz, Pru p 3 (LTP) content in peach extracts, Allergy 57 (2002) 1071-1075. 
[20] O.V. Brenna, E.A. Pastorello, L. Farioli, V. Pravettoni, C. Pompei, Presence of allergenic proteins in different peach (Prunus persica) cultivars and dependance of their content on fruit ripening, J. Agric. Food Chem. 52 (2004) 7997-8000.

[21] A. Diaz-Perales, G. Garcia-Casado, R. Sanchez-Monge, F.J. GarciaSelles, D. Barber, G. Salcedo, cDNA cloning and heterologous expression of the major allergens from peach and apple belonging to the lipid-transfer protein family, Clin. Exp. Allergy 3 (2002) 87-92.

[22] P. Tonutti, C. Bonghi, B. Ruperti, G.B. Tornielli, A. Ramina, Ethylene evolution and 1-aminocyclopropane-1-carboxylate oxidase gene expression during early development and ripening of peach fruit, J. Am. Soc. Hort. Sci. 1122 (1997) 642-647.

[23] B. Ruperti, C. Bonghi, A. Rasori, A. Ramina, P. Tonutti, Characterization and expression of two members of the peach 1-aminocyclopropane-1carboxylate oxidase gene family, Physiol. Plant. 111 (2001) 336344.

[24] V. Dal Cin, M. Danesin, F.M. Rizzini, A. Ramina, RNA extraction from plant tissues: the use of calcium to precipitate contaminating pectic sugars, Mol. Biotechnol. 31 (2005) 113-120.

[25] P. Vos, R. Hogers, M. Bleeker, M. Reijans, T. van de Lee, M. Hornes, A. Frijters, J. Pot, J. Peleman, M.E. Kuiper, M. Zabeau, AFLP ${ }^{\mathrm{TM}}$ : a new technique for DNA fingerprinting, Nucleic Acids Res. 23 (1995) 44074414.

[26] J.D. Bendtsen, H. Nielsen, G. von Heijne, S. Brunak, Improved prediction of signal peptides: SignalP 3.0, J. Mol. Biol. 340 (2004) 783-795.

[27] H. Nielsen, J. Engelbrecht, S. Brunak, G. von Heijne, Identification of prokaryotic and eukaryotic signal peptides and prediction of their cleavage sites, Prot. Eng. 10 (1997) 1-6.

[28] H. Nielsen, A. Krogh, Prediction of signal peptides and signal anchors by a hidden Markov model, in: Proceedings of the Sixth International Conference on Intelligent Systems for Molecular Biology (ISMB 6), AAAI Press, Menlo Park, California, 1998, pp. 122-130.

[29] S.M. Hebsgaard, P.G. Korning, N. Tolstrup, J. Engelbrecht, P. Rouze, S. Brunak, Splice site prediction in Arabidopsis thaliana DNA by combining local and global sequence information, Nucleic Acids Res. 24 (1996) 3439-3452.

[30] M. Lescot, P. Déhais, G. Thijs, K. Marchal, Y. Moreau, Y. Van de Peer, P. Rouzé, S. Rombauts, PlantCARE, a database of plant cis-acting regulatory elements and a portal to tools for in silico analysis of promoter sequences, Nucleic Acids Res. 30 (2002) 325-327.
[31] K. Higo, Y. Ugawa, M. Iwamoto, T. Korenaga, Plant cis-acting regulatory DNA elements (PLACE) database, Nucleic Acids Res. 27 (1999) 297-300.

[32] C.C. Hach, S.V. Brayton, A.B. Kopelove, A powerful Kjeldahl nitrogen method using peroxymonosulfuric acid, J. Agric. Food Chem. 33 (1985) $1117-1123$.

[33] U.K. Laemmli, Cleavage of structural proteins during the assembly of the head of bacteriophage T4, Nature 227 (1970) 680-685.

[34] P. Koenig, H. Stagmann, M.L. Paul, Proteins subunits in the potato virus Xgroup: determination of the molecular weights by polyacrilamyde electrophoresis, Biochim. Biophys. Acta 207 (1970) 184-189.

[35] E.A. Pastorello, A.M. Robino, Clinical role of lipid transfer proteins in food allergy, Mol. Nutr. Food Res. 48 (2004) 356-362.

[36] A. Papadopoulou, R.A. Frazier, Characterization of protein-poliphenol interactions, Trends Food Sci. Technol. 15 (2004) 186-190.

[37] G. García-Casado, L.F. Pacios, A. Díaz-Perales, R. Sánchez-Monge, M. Lombardero, García-Selles, F.J. Florentino Polo, D. Barber, G. Salcedo, Identification of IgE-binding epitopes of the major peach allergen Pru p 3, J. Allergy Clin. Immunol. 112 (2003) 599-605.

[38] Z. Wu, J.K. Burns, Isolation and characterization of a cDNA encoding a lipid transfer protein expressed in 'Valencia' orange during abscission, J. Exp. Bot. 54 (2003) 1183-1191.

[39] H.C. Liu, R.G. Creech, J.N. Jenkins, D.P. Ma, Cloning and promoter analysis of the cotton lipid transfer protein gene Ltp3, Biochim. Biophys. Acta 1487 (2000) 106-111.

[40] F. Vignols, G. Lund, S. Pammi, D. Trémousaygue, F. Grellet, J.C. Kader, P. Puigdomènech, M. Delseny, Characterization of a rice gene coding for a lipid transfer protein, Gene 142 (1994) 265-270.

[41] J. Pelese-Siebenbourg, C. Caellas, J.K. Kader, M. Delseny, P. Puigdomenech, A pair of genes coding for lipid-transfer protein in Sorghum vulgare, Gene 148 (1994) 305-308.

[42] J. Pyee, P.E. Kolattukudy, The gene for the major cuticular wax-associated protein and three homologous genes from broccoli (Brassica oleracea) and their expression patterns, Plant J. 7 (1995) 49-59.

[43] A. Molina, I. Diaz, I.K. Vasil, P. Carbonero, F. Garcia-Olmedo, Two coldinducible genes encoding lipid transfer protein LTP4 from barley show differential responses to bacterial pathogens, Mol. Gen. Genet. 252 (1996) $162-168$.

[44] D.A. Moneret-Vautrin, G. Kanny, Update on threshold doses of food allergens: implications for patients and the food industry, Curr. Opin. Allergy Clin. Immunol. 4 (2004) 215-219. 